\title{
The Knowledge Base and Text Recall: Evidence from a Short-Term Longitudinal Study
}

\author{
Wolfgang Schneider AND JoAChim Körkel \\ Max-Planck Institute for Psychological Research
}

\begin{abstract}
In a short-term longitudinal study, we investigated how domain-specific knowledge in soccer influences the amount of text recall and comprehension in elementary school and junior high school children of high and low overall aptitudes. Both level of soccer knowledge and overall aptitude were varied in a factorial design. Third, fifth, and seventh grade children were given several measures of text recall and comprehension and were retested on these measures about 1 year later. Performance was more a function of soccer knowledge than of aptitude level. 1989 Academic Press, Inc.
\end{abstract}

Studies using the expert-novice paradigm (e.g., Chi, 1978; Chi, Glaser, \& Rees, 1982; Chiesi, Spilich, \& Voss, 1979; Spilich, Vesonder, Chiesi, \& Voss, 1979) have convincingly demonstrated the role of domain-specific knowledge in explaining patterns of memory performance. The research problem as posed in early studies of domain-specific expertise was whether overall aptitude or domain-specific knowledge would prove to be more important in distinguishing expert and novice performances. The overall greater speed and accuracy characterizing an expert's performance lead several researchers to believe that expertise in a given domain might reflect superior overall aptitude (cf. Gagné, 1985; Walker, 1987, for reviews). However, subsequent research failed to confirm any type of "general superiority" hypothesis (cf. Ericsson \& Crutcher, in press). That is, experts and novices in a domain typically did not differ with regard to overall aptitude or general reasoning skills. Accordingly, the superiority of the experts' memory for material in their domain of competence was attributed to the impact of their rich domain-specific knowledge. This knowledge base also enabled them to automatically recognize many domain-relevant patterns and to solve domain-related problems.

Given the powerful effects of domain-specific knowledge, a related question is whether rich knowledge in a specific domain can compensate for low overall aptitude. Since most early studies comparing experts and

This research was supported by a grant from the Stiftung Volkswagenwerk (AZ II 36 192). Parts of the paper were presented at the annual meeting of the American Educational Research Association in New Orleans, April 1988. Address correspondence and reprint requests to Wolfgang Schneider, Max-Planck Institute for Psychological Research, Leopoldstrasse 24, D-8000 München 40, West Germany. 
novices used subjects whose overall aptitude was high (e.g., college students, physics professors), none of the data in these research efforts were relevant to this problem.

Several recently published studies of expertise, however, partially filled this gap. For example, Ceci and Liker (1986) investigated decisionmaking rules of highly expert gamblers at the racetrack. Ceci and Liker demonstrated that those experts who appeared to be operating at low levels of intellectual functioning (e.g., IQs in the 80s) were capable of complex classification and reasoning processes when the stimuli were very familiar to them. Two recent studies dealing with expertise in the domain of baseball also explored possible effects of aptitude differences on text processing in the designated domains. Walker (1987) compared high- and low-aptitude adults who were either baseball experts or novices. When presented with a baseball passage, the low-aptitude/ high-knowledge subjects recalled more text information than the high-aptitude/low-knowledge subjects. The two expert groups who differed with regard to general aptitude recalled similar amounts of important information and made equivalent numbers of goal-relevant inferences. Recht and Leslie (1988) investigated how domain-specific knowledge influences text recall and comprehension of high-knowledge versus low-knowledge seventh- and eighth-grade children differing in reading ability (which is significantly correlated with general aptitude). Children had to read a baseball passage and then reenact the action described in the text, retell the story, summarize the text, and sort sentences chosen randomly from the passage on the basis of importance of ideas in the text. Children with greater knowledge of baseball outperformed children with less knowledge on all dependent variables. There was no main effect of reading ability and no significant interaction between rcading ability and domain-specific knowledge.

There is also evidence that these results can be generalized to younger children and to a different domain (i.e., soccer). Schneider, Körkel, and Weinert (in press) compared text recall and comprehension of third-, fifth-, and seventh-grade soccer experts and novices differing in intellectual ability. Their task was to acquire and use new information in the domain of soccer. Both level of soccer knowledge and overall aptitude were varied in a factorial design. Prior knowledge once again compensated for deficits in overall aptitude: No significant differences between high-aptitude and low-aptitude soccer experts were detected. Moreover, low-aptitude experts outperformed high-aptitude novices on all memory and comprehension measures.

The major purpose of the present study was to validate and extend the findings reported in the cross-sectional report by Schneider et al. (in 
press). Most subjects were retested about 1 year later when they were in grades 4,6 , and 8 . We were particularly interested in obtaining more information concerning the following four points: (1) were there any gains in soccer knowledge over time, and how reliable was the expert-novice classification procedure which used the median of the distribution as a cutoff point; (2) were there any significant developmental changes in memory performance over the period of 1 year, (3) was it possible to replicate the major findings obtained by Schneider et al. (in press) about 1 year later, and (4) would the inclusion of additional measures of memory performance yield a similar pattern of results?

\section{METHOD}

Subjects, Materials, and Design

A total of 372 middle-class children at three age levels were available for the replication study. Subjects were 74 fourth graders (mean age, 10-3; range, 9-5 to 11-0), 158 sixth graders (mean age, 12-6; range, 11-6 to 13-8), and 140 eighth graders (mean age, 14-5; range, 13-8 to 15-6) from rural and urban schools in the Heidelberg area. There were approximately equal numbers of boys and girls at each age.

All testing was done in group sessions. Most of the measures administered the year before were administered on the second occasion highlighted here. See Table 1 for a detailed list of measures included in the first assessment and in this assessment.

A 13-item questionnaire was used to assess children's knowledge about soccer. Ten multiple-choice items tapped subjects' knowledge about soccer rules, whereas the remaining three items assessed knowledge about important soccer events. Each item on the questionnaire was given a score of 1 or 0 (maximum score of 13). For each age group, children with scores above the median were classified as soccer experts, and those with scores below the median were considered soccer novices. To identify high- and low-aptitude children within the groups of soccer experts and novices, children's scores on verbal and nonverbal intelligence tests (the verbal subtests of a German cognitive ability test and the Culture-Fair Intelligence test) were considered.

TABLE 1

Measures Used in the Short-Term Longitudinal Study

\begin{tabular}{lcc}
\hline \multicolumn{1}{c}{ Measures } & $\begin{array}{c}\text { Collected } \\
\text { year earlier }\end{array}$ & $\begin{array}{c}\text { Collected } \\
\text { now }\end{array}$ \\
\hline Intelligence & Yes & No \\
Soccer Knowledge Test & Yes & Yes \\
Memory for Text Details & Yes & Yes \\
Text Recognition & No & Yes \\
Importance Rating Task & Yes & Yes \\
Drawing of Inferences & Yes & Yes \\
Detection of Contradictions & Yes & Yes \\
Feeling-of-Knowing & No & Yes \\
\hline
\end{tabular}


At each grade level, mean raw scores based on these tests were computed for each subject. Those subjects with above-average IQ scores were classified as high-aptitude subjects, whereas those children scoring low in both intelligence tests were classified as lowaptitude subjects. As a consequence, four groups were differentiated at each grade level: high-aptitude/high-knowledge, low-aptitude/high-knowledge, high-aptitude/low-knowledge, and low-aptitude/low-knowledge subjects.

All subjects were presented with a narrative text dealing with a soccer game. The story was about a young soccer player's experiences in an important match. After a short description of the young hero and his activities before the game, the course of action during the game was described in detail. The story ended with a description of the hero's physical and psychological condition after the game was over.

Precautions were taken to ensure that most parts of the story were easily understandable for novices. Amstad's (1978) version of the Flesch formula was used to assess text readability. This formula yields values ranging from 0 (low readability) to 100 (high readability). The average score obtained for our story $(\bar{x}=80)$ indicated that the text was easily readable for the different age groups under study. In addition, a structural analysis of the text based on the grammar of Mandler and Johnson (1977; Johnson \& Mandler, 1980) revealed that the story could be considered simple and well-structured according to the criteria of these authors.

However, there were a few exceptions to this rule. Occasionally, sentences were shortened; that is, important information was omitted that had to be inferred by the reader. Moreover, several contradictions were built into the text that could only be detected by careful reading. For example, the hero was first described as a fast soccer player, but was later referred to as very slow and sluggish. While prior knowledge about soccer was important to draw correct inferences, it was not always necessary to detect the contradictions in the text.

'The story was taped and presented twice to the subjects. While listening to the story, they also had opportunity to simultaneously read a written version. About $15 \mathrm{~min}$ later, subjects were given a 10-item questionnaire that tapped children's memory for text details, their detection of contradictions in the text, and their ability to draw correct inferences. Each item on the questionnaire was given a score of 1 or 0 ; a maximum score of 4 was possible for the memory variable and 3 for the text comprehension variables.

Further, an importance rating procedure was used. The importance rating procedure is a very popular tool in the area of text memory and comprehension (cf. Brown, Bransford, Ferrara, \& Campione, 1983, for a review). The version used in this study required the children to select and underline those 10 sentences in the soccer text that they considered the most important and necessary for an efficient reproduction of the text. Children's importance ratings were then compared with an "ideal" importance rating of the text based on the judgments of 20 adult soccer experts (students and faculty members of different departments at the University of Heidelberg). One point was given when a sentence judged as important corresponded with an "objectively" important sentence selected by the adult experts (maximum score of 10 ).

Finally, a multiple-choice test was additionally provided to assess children's recognition memory. Again, all 32 sentences of the soccer story were presented at the very end of the session (i.e., approximately $30 \mathrm{~min}$ after the importance rating task). However, this time one word was missing in each sentence, and three alternatives (the target and two similar distractor items) were presented. The children's task was to select the correct item for sentence completion and also to indicate each time how confident they were that they actually chose the correct item. The number of correct choices was used as an indicator of subject's recognition memory, whereas their feeling-of-knowing judgments were used as indicators of metacognitive awareness. 


\section{RESULTS}

\section{Stability of the Expert-Novice Classification}

First, soccer experts and novices were defined according to the results of the multiple-choice test tapping soccer knowledge. Children scoring above the median were classified as soccer novices. Table 2 shows the means and standard deviations as a function of grade.

A 3 (Grade) $\times 2$ (Expertise) $\times 2$ (Aptitude) repeated measurement analysis of variance conducted on the soccer knowledge test showed significant main effects of Grade, $F(2,360)=7.33, p<.01$, and Expertise, $F(1,360)=34.41, p<.01$. Subsequent Student-Newman-Keuls tests revealed that significant increases in soccer test performance were obtained for the fourth graders but not for the sixth and eighth graders. Significant differences between experts and novices were found at each age level. Whereas experts' performance improved over time, this was not true for soccer novices. There was no main effect of aptitude, and no significant interactions were found.

Stability of the expert-novice classification was generally high. About $78 \%$ of the fourth graders, $83 \%$ of the sixth graders, and $92 \%$ of the eighth graders were consistently classified as soccer experts or novices on both occasions.

\section{Developmental Changes in the Text Recall and \\ Comprehension Measures}

Analyses assessing developmental changes were based on those 318 subjects who were consistently classified as soccer experts or novices on both occasions. A 3 (Grade) $\times 2$ (Expertise) $\times 2$ (Aptitude) multivariate repeated measures ANOVA conducted on Memory for Text Details, Correct Inferences, Detection of Contradictions, and Importance Ratings showed a significant main effect of Grade, $F(11,306)=13.63, p<.01$.

TABLE 2

Means and Standard Deviations (In Parentheses) for the Soccer Knowledge Test, as a Function of Grade

\begin{tabular}{cccc}
\hline & \multicolumn{3}{c}{ Soccer knowledge } \\
\cline { 2 - 4 } & Wave 1 & Wave 2 & $N$ \\
\hline Grades 3/4 & 5.92 & 6.74 & \\
& $(2.29)$ & $(2.13)$ & 74 \\
Grades 5/6 & 8.25 & 8.01 & 158 \\
& $(2.23)$ & $(2.12)$ & \\
Grades 7/8 & 8.58 & 8.62 & 140 \\
& $(1.98)$ & $(1.78)$ & \\
\hline
\end{tabular}


There were no other main effects or interactions. Univariate analyses revealed that the pattern of results was similar for all dependent measures included in the MANOVA. Significant overall performance increases over time were observed for all measures under investigation. The corresponding $F \mathrm{~s}(2,306)$ for the Memory for Text Details, Correct Inferences, Detection of Contradiction, and Importance Rating Variables were $17.83,13.29,41.48$, and 80.60, respectively (all $p s<.01$ ). Subsequent Student-Newman-Keuls tests revealed that fourth graders always gained significantly more than the two other age groups which did not differ from each other.

The research question of primary interest was whether the findings reported at the first testing (cf. Schneider et al., in press) could be replicated 1 year later. Four 3 (Grade) $\times 2$ (Expertise) $\times 2$ (Aptitude) factorial analyses of variances were conducted on post-test Memory for Text Details, Correct Inferences, Detection of Contradictions, and Importance Ratings.

With regard to Memory for Text Details, the results could be replicated. Significant main effects were found for Grade, $F(2,360)=14.60, p$ $<.01$, and Expertise, $F(1,360)=8.05, p<.01$. There was no effect of Aptitude, and no significant interactions were found. Post-hoc comparisons (Student-Newman-Keuls tests) revealed that eighth graders recalled more than sixth and fourth graders who did not differ from each other. As expected, experts outperformed novices.

The most impressive findings concerned the two metacognitive measures (i.e., Correct Inferences and Detection of Contradictions). Figure 1 contains the means for these two variables obtained at this second testing as functions of Grade, Expertise, and Aptitude. Mean longitudinal gains in each variable are also depicted in Fig. 1.

As to the Correct Inference variable, significant main effects were found for Grade, $F(2,360)=7.58, p<.01$, and Expertise, $F(1,360)=$ $114.32, p<.01$. There was no main effect of Aptitude, and no significant interactions were found. Subsequent Student-Newman-Keuls tests revealed that both sixth and eighth graders drew more correct inferences than fourth graders but did not differ from each other. Again, experts outperformed novices.

Results for the Detection of Contradictions variable were similar. Main effects were found for Grade, $F(2,360)=13.79, p<.01$, and Expertise, $F(1,360)=137.55, p<.01$. Again, there were no effects of Aptitude, and no significant interactions. Subsequent Student-Newman-Keuls showed that eighth graders scored higher than sixth graders, who in turn outperformed fourth graders. Consistent with the previously reported data, experts did better than novices. 

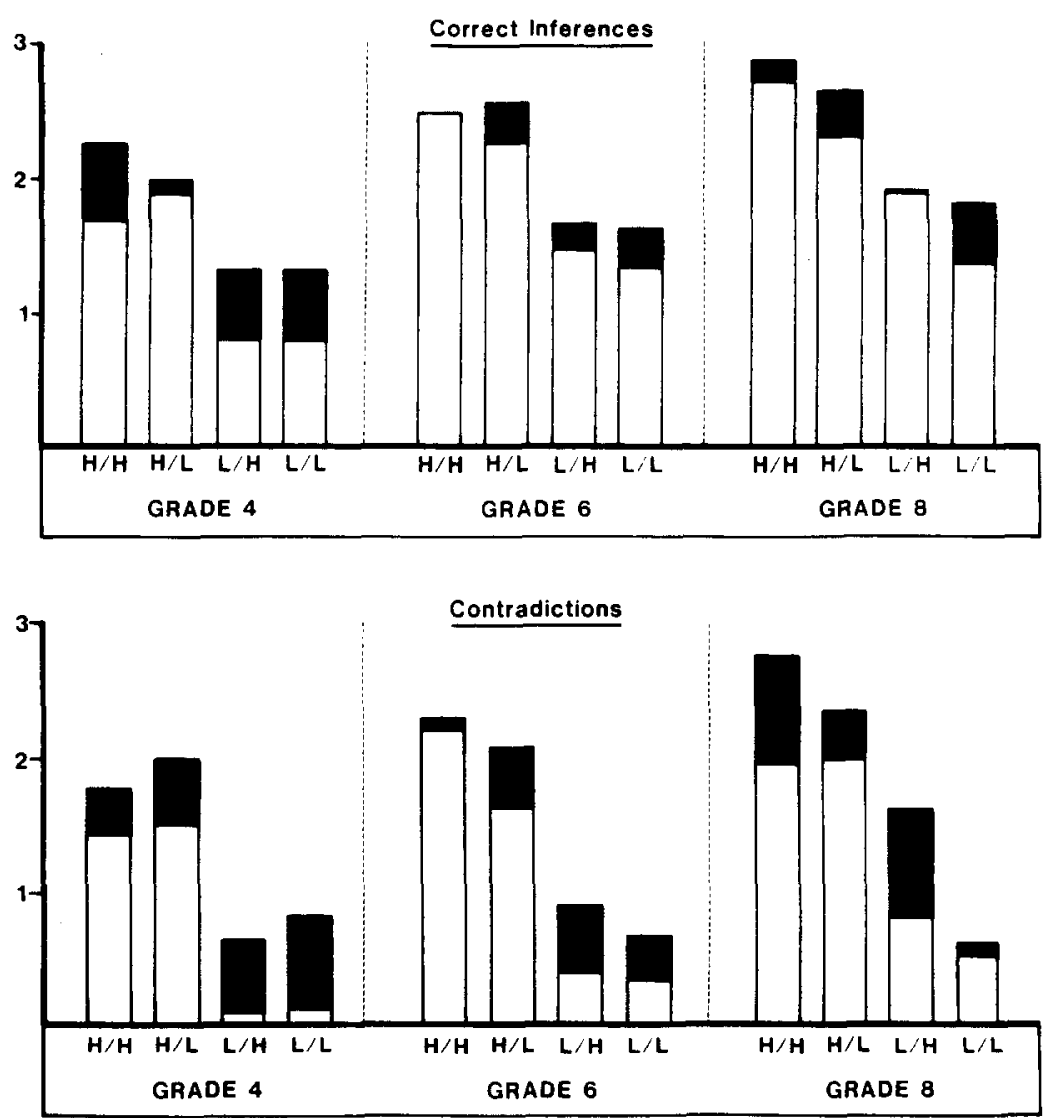

H/H = HIGH KNOWLEDGE / HIGH APTITUDE

H/L = HIGH KNOWLEDGE / LOW APTITUDE

$L / H=L O W$ KNOWLEDGE / HIGH APTITUDE

$\mathbf{L} / \mathbf{L}=$ LOW KNOWLEDGE / LOW APTITUDE

Fig. 1. Mean gains obtained for Correct Inferences and Detection of Contradictions (indicated by black bars), as a function of Grade and Expertise/Aptitude.

Different results were obtained for the Importance Rating task. Means and standard deviations for this task are given in Table 3 . Significant main effects were found for Grade, $F(2,360)=26.85, p<.01$, Expertise, $F(1,360)=16.93, p<.01$, and Aptitude, $F(1,360)=29.93, p<.01$. There were no significant interactions. Subsequent Student-Newman-Keuls tests revealed that eighth graders outperformed sixth graders, who in turn were better than fourth graders. Experts were better than novices, and high-aptitude subjects outperformed children with low general ability. Thus, the Importance Rating task was the only one to show that general 
TABLE 3

Means and Standard Deviations (in Parentheses) for the Importance Rating, Text Recognition, and Feeling of Knowing Variables as a Function of Grade, EXPERTISE, AND APTITUDE

\begin{tabular}{|c|c|c|c|}
\hline & \multicolumn{3}{|c|}{ Variables } \\
\hline & $\begin{array}{c}\text { Importance } \\
\text { Rating } \\
(\max =10)\end{array}$ & $\begin{array}{c}\text { Text } \\
\text { Recognition } \\
(\max =32)\end{array}$ & $\begin{array}{c}\text { Feeling- } \\
\text { of-knowing } \\
(\max =32)\end{array}$ \\
\hline \multicolumn{4}{|l|}{ Grade 4} \\
\hline \multicolumn{4}{|l|}{ Experts } \\
\hline High-aptitude & $5.70(1.49)$ & $26.50(3.72)$ & $21.60(3.50)$ \\
\hline Low-aptitude & $4.92(1.62)$ & $26.33(3.08)$ & $22.92(3.96)$ \\
\hline \multicolumn{4}{|l|}{ Novices } \\
\hline High-aptitude & $4.53(1.30)$ & $27.53(2.72)$ & $24.20(4.44)$ \\
\hline Low-aptitude & $3.95(1.29)$ & $24.97(3.44)$ & $23.72(3.21)$ \\
\hline \multicolumn{4}{|l|}{ Grade 6} \\
\hline \multicolumn{4}{|l|}{ Experts } \\
\hline High-Aptitude & $5.81(1.32)$ & $27.68(2.28)$ & $24.93(3.00)$ \\
\hline Low-aptitude & $5.00(1.29)$ & $26.10(3.74)$ & $23.38(3.26)$ \\
\hline \multicolumn{4}{|l|}{ Novices } \\
\hline High-aptitude & $5.33(1.43)$ & $26.86(3.61)$ & $23.44(2.96)$ \\
\hline Low-aptitude & $4.42(1.37)$ & $23.98(4.30)$ & $22.58(3.57)$ \\
\hline \multicolumn{4}{|l|}{ Grade 8} \\
\hline \multicolumn{4}{|l|}{ Experts } \\
\hline High-aptitude & $6.08(1.08)$ & $26.54(3.74)$ & $23.54(4.65)$ \\
\hline Low-aptitude & $5.77(1.31)$ & $27.08(3.37)$ & $23.30(3.55)$ \\
\hline \multicolumn{4}{|l|}{ Novices } \\
\hline High-aptitude & $5.91(1.28)$ & $26.72(2.84)$ & $23.37(3.29)$ \\
\hline Low-aptitude & $5.13(1.01)$ & $25.91(4.18)$ & $23.26(3.89)$ \\
\hline
\end{tabular}

aptitude makes a difference: Domain-specific expertise could not compensate for low overall aptitude when the task was to rate the importance of text units for subsequent remembering.

The final set of analyses was performed on the text recognition and feeling-of-knowing measures that were only included at this second assessment. Means and standard deviations for these measures are given in Table 3.

These data were analyzed in two 3 (Grade) $\times 2$ (Expertise) $\times 2$ (Aptitude) factorial analyses of variance with Text Recognition and Feelingof-Knowing as dependent variables. With regard to Text Recognition, significant main effects were found for Grade, $F(2,360)=4.08, p<.05$, Expertise, $F(1,360)=4.37, p<.05$, and Aptitude, $F(1,360)=30.87, p<$ .01. Subsequent Student-Newman-Keuls tests revealed that eighth graders were better than sixth and fourth graders who showed equivalent performance. Experts scored higher than novices, and high-aptitude sub- 
jects outperformed low-aptitude subjects. There were no significant interactions.

As to Feeling-of-Knowing, the analyses yielded unexpected findings. No main effects were found, and there were also no significant interactions. Obviously, most subjects were able to assess their performance rather accurately in the multiple-choice text recognition test, regardless of age, aptitude, or expertise.

\section{DISCUSSION}

The short-term longitudinal study of soccer experts and novices reported in this paper represents an extension of the Schneider et al. (in press) study, providing information on aspects of stability and developmental change in soccer knowledge and domain-specific text processing.

One important issue was whether the classification of soccer experts and novices would remain stable over the period of about 1 year. The results clearly showed that this was the case. Interestingly, the stability of the expert-novice classification increased with age, indicating highly stable classification rates for the oldest children in the sample (i.e., eighth graders). These findings seem particularly impressive because experts and novices were classified according to the median of the distribution and thus did not represent extreme groups of highly knowledgeable versus completely inexperienced subjects.

The analysis of developmental changes over time revealed that there were significant increases for all variables measured at the first testing. That is, on average all children improved their performance in the Memory for Text Details, Drawing Inferences, the Detection of Contradictions, and Importance Rating tasks. Somewhat surprisingly, performance gains were neither affected by general aptitude nor by soccer expertise.

The most important question was whether the pattern of findings obtained for the cross-sectional data (cf. Schneider et al., in press) would prove to be stable over time. As a main rcsult of the short-term longitudinal study, it turned out that most findings reported in the earlier investigation were obtained again at this second testing. That is, when soccer experts and novices were compared on their ability to memorize text details, to draw inferences, and to detect contradictions in the text on a soccer game, experts outperformed novices on all three outcome measures. More importantly, the distinction of low- and high-aptitude soccer experts and novices did not change this pattern of findings. That is, highand low-aptitude experts did not differ from each other, and there were also no significant differences between high- and low-aptitude soccer novices. Accordingly, the data provide evidence for the fact that high domain-specific knowledge can compensate for low general aptitude.

It should be noted, however, that our replication attempts were not 
completely successful. Analyses on the Importance Rating task revealed a significant main effect of Aptitude, thus indicating that domain-specific knowledge cannot compensate for low aptitude when it comes to identifying those sentences of a story most important for accurate text comprehension. These findings are not consistent with those obtained on the first assessment. They also do not correspond with the findings reported by Recht and Leslie (1988) who found a main effect of prior knowledge but no effect of ability for their idea importance measure. Note that significant effects of aptitude on performance in the importance rating task were only found for the second measurement point of our study. It seems that the high-aptitude children particularly benefitted from the repeated presentation of the task, regardless of age. However, the reason for this developmental change remains unclear to us.

Similarly, the results obtained for the two variables measured only at the second testing were not in accord with those reported by Schneider $e t$ al. (in press). With regard to Text Recognition, main effects of Aptitude were found in addition to effects of Grade and Expertise. This finding is not consistent with the one obtained for a cloze test described in Schneider et al. (in press, Experiment 2), where no effects of Aptitude were detected. This inconsistency in findings may be due to differences in tasks. While a cloze test was used by Schneider $e$ t al. (in press), a multiple choice test was given in the replication study. That is, whereas cued recall was requested in the earlier study, recognition memory was required for the multiple-choice task. The implication is that the multiple-choice task was easier than the cloze test. Apparently, high-aptitude novices benefitted most from this procedural change, indicating that the generally easy task was particularly stimulating for this subgroup of children.

Given the fact that the Text Recognition task was generally easy, it no longer seems surprising that there were no significant differences in the feeling-of-knowing task. On average, most children were rather accurate in judging whether their responses were correct or not. Appropriate feeling-of-knowing statements were found for about $70 \%$ of the items, regardless of children's age, expertise, or aptitude. It appears, then, that the generally easy Text Recognition task is at least partially responsible for the unexpected findings for the Feeling-of-Knowing task. The fact that the text recognition task was very easy makes it difficult to interpret the feeling-of-knowing data. We know from the literature that children often give high confidence ratings (see Schneider \& Pressley, 1989). Thus, their ratings may just happen to be accurate when performance is high. It could be, then, that the accuracy scores obtained in our feeling-of-knowing task may not reflect true metacognitive competencies.

Taken together, however, the findings of the present study strongly support the importance of domain knowledge to effective cognitive pro- 
cessing. The findings suggest that domain expertise can compensate for overall low ability on domain-related cognitive processing tasks. That is, both the results of Schneider et al. (in press) and the short-term longitudinal study support the conclusion that children's prior knowledge about text contents is a much more powerful predictor of their text comprehension and recall than their overall intellectual abilities, particularly when the knowledge base is large. They also demonstrate that the findings obtained by Recht and Leslie (1988) and Walker (1987) can be generalized to younger subjects and other domains.

In our view, these findings have important instructional implications. Obviously, low-aptitude learners can perform like high-aptitude learners in a domain where they have acquired high levels of knowledge. An interesting result of our study was that even low-aptitude fourth-grade soccer experts were able to adequately judge the importance of specific text units for later recall, a competence usually not emerging before grade 5 or 6 (see Schneider et al., in press). In other words, most young lowaptitude soccer experts were able to show competencies related to academic success in school when they were highly familiar with the contents of the task. While we acknowledge that differences in knowledge base are not the only important factors in explaining developmental and individual differences in cognitive performance, we see differences in knowledge base as playing a major role. As pointed out by Muir and Bjorklund (in press), education systems should prepare children for the future by providing them with the broad-based knowledge they will need to participate in our highly technical and global economy. It appears, then, that current instructional programs might put more emphasis on enriching children's knowledge base in different domains.

\section{REFERENCES}

AMSTAD, T. (1978). Wie verständlich sind unsere Zeitungen? Unpublished dissertation, Zurich.

Brown, A. L., Bransford, J. D., Ferrara, R. A., \& Campione, J. C. (1983). Learning, remembering, and understanding. In J. H. Flavell \& E. M. Markman (Eds.), Handbook of child psychology: Cognitive development (Vol. 3, pp. 77-166). New York: Wiley.

CeCI, S. J., \& LIKER, J. (1986). A day at the races: The study of IQ, expertise, and cognitive complexity. Journal of Experimental Psychology: General, 115, 225-226.

CHI, M. T. H. (1978). Knowledge structures and memory development. In R. S. Siegler (Ed.), Children's thinking: What develops? (pp. 73-96). Hillsdale, NJ: Erlbaum.

Chi, M. T. H., Glaser, R., \& ReEs, E. (1982). Expertise in problem solving. In R. J. Sternberg (Ed.), Advances in the psychology of human intelligence (Vol. 1, pp. 7-75). Hillsdale, NJ: Erlbaum.

ChIEsI, H. L., SpILICH, G. J., \& Voss, J. F. (1979). Acquisition of domain-related information in relation to high and low domain knowledge. Journal of Verbal Learning and Verbal Behavior, 18, 257-274.

Ericsson, K. A., \& CRUTCher, R. J. (in press). The nature of exceptional performance. In 
P. B. Baltes, D. L. Featherman, \& R. M. Lerner (Eds.), Life-span development and behavior (Vol. 10). Hillsdale, NJ: Erlbaum.

GAGNE, E. (1985). The cognitive psychology of school learning. Boston: Little, Brown.

Johnson, N. S., \& MANDLER, J. M. (1980). A tale of two structures: Underlying surface forms in stories. Poetics, 9, 51-86.

MANDLER, J. M., \& Johnson, N. S. (1977). Remembrance of things parsed: Story structure and recall. Cognitive Psychology, 9, 111-151.

MuiR, J. E., \& BJoRKLund, D. F. (in press). Developmental and individual differences in children's memory strategies: The role of knowledge. In W. Schneider \& F. E. Weinert (Eds.), Interactions among aptitudes, strategies, and knowledge in cognitive performance. New York: Springer-Verlag.

ReCht, D. R., \& LESLIE, L. (1988). Effect of prior knowledge on good and poor readers' memory of text. Journal of Educational Psychology, 80, 16-20.

Schneider, W., Körkel, J., \& Weinert, F. E. (in press). Domain-specific knowledge and memory performance: A comparison of high- and low-aptitude children. Journal of Educational Psychology.

Schneider, W., \& Pressley, M. (1989). Memory development between 2 and 20. New York: Springer-Verlag.

Spilich, G. J., Vesonder, G. T., Chiesi, H. L., \& Voss, J. F. (1979). Text processing of domain-rclated information for individuals with high and low domain knowledge. Journal of Verbal Learning and Verbal Behavior, 18, 275-290.

WALKER, C. H. (1987). Relative importance of domain knowledge and overall aptitude on acquisition of domain-related information. Cognition and Instruction, 4, 25-42. 